\title{
Optimal Learning Strategies for Decision Making from Global Perspective
}

\author{
Yoshinori Naruse, Akiko Nagayama \\ National Institute of Technology, Toyama College
}

\begin{abstract}
Two educational methods for lessons in English were used to improve students' learning and communication skills. Practical results suggest that the following two points are effective to develop problem-based learning in English using robotic cars and trains in future instruction. Students should be encouraged to concentrate on their tasks through solution of a problem, instead of particularly communicating only in English. Students are also encouraged to discuss collaborative activities in advance and to deepen their knowledge so that they can achieve better communication.
\end{abstract}

\section{Introduction}

Two education issues are heavily discussed in Japan. One is cultivation of the ability to solve a problem set by students. To carry out problem-based learning, it is presumably important that teachers make students aware of the learning process: to find a problem, to think about steps to solve the problem, to measure an outcome produced by themselves after following the steps, to revise them, and to develop their learning process according to a Plan-Do-CheckAct (PDCA) cycle. Moreover, as often as possible, teachers should encourage students to grapple with some problem undertaken on their own initiative because students have become accustomed to teacher-centered learning [1].

The other is how to cultivate skills to cope with a globalized society. Many Japanese companies are finding larger markets overseas, doing business, and making technological innovations through their global business activities. They have established branch factories in many foreign countries. Many Japanese engineers must develop production facilities in foreign countries and engage in direct negotiations with people there to boost their businesses.

However, the difficulty of the Japanese mother tongue induces Japanese people to make decisions while thinking in Japanese. Because of such situations, the fact is that they have difficulty in the gap of their language skills between Japanese language and a foreign language.

Rarely are Japanese people trained to summarize and express their ideas in English or in any other language. They are not good at having discussions with foreign people whose cultural background differs from their own, or at advancing their original opinions clearly. To keep pace with globalization, students in Japan must bring their ideas together immediately, express their opinions in English, and discuss various problems in English, devoting due attention to others' comments and ideas.

Although International Internship Programs and teaching programs involving native teachers have been popular in Japan [2][3], the education curriculum in Japan under the present circumstances does not provide sufficient time to train students to acquire such communication skills in English. The issue related to raising English skills is becoming an urgent topic in the discussion of how to thrive in a globalized society and how to foster English communication skills in education in Japan. Videoconferencing has been tried several times, leaving several problems to be solved.

The authors conducted two educational practices: giving lessons in English so that students can learn a specialized subject in English, and improving students' communication skills in English through interaction with students from abroad.

\section{Development and use of decision- making method teaching materials}

The authors developed robotic cars and trains as teaching materials for students in different years from lower years to higher years [4]. Robotic cars were developed early as teaching materials. They are portable and handy to use at any place as teaching materials. The teaching process that incorporates robotic cars to make students' learning more active is described below. Learning data are also presented.

1) The combined data of the value of electrical power (maximum value is $100 \%$ ) and its driving time are input into a robotic car's program.

2) The car starts to run by executing a program after pushing a starting button.

3) It displays the results of consumption energy (J), driving distance $(\mathrm{m})$, and driving time $(\mathrm{s})$ on the display.

4) It stops running automatically when the energy consumption exceeds the limit value, even if the program is not executed completely. 
The first process described above displays an input scene for a robotic car. Data can be transmitted to a robotic car by connecting a USB cable to a robotic car. Running results can be displayed on a portable display set on a robotic car. Then students can determine its running performance while examining its running results.

The robotic-train teaching process is the same as that used with robotic cars: it is designed to produce a running program on a computer, to put it into operation, to apply electrical current to the rails, and to run a robotic train. A course including up-slopes and down-slopes was built to help students compare running conditions.

\section{Teaching materials for problem-based learning}

\subsection{Teaching materials for decision-making learning}

People who are actively involved in business are often asked to make optimum decisions in various situations. An optimum decision means that a person can make a rational decision, producing possible choices based on all available information. More precisely, when a person faces such a situation as making a prompt decision, the person must collect as much appropriate information as possible that derives from an objective viewpoint.

Moreover, the person must analyze and organize information as good materials to judge, and must arrange the materials into two categories having higher or lower priority. Finally, the person must conduct decision-making rationally and synthetically based on all available information.

Decision-making situations often arise in school education. In many cases, they can help students recognize the importance of decision-making methods [5]. Nevertheless, it is difficult to say that sufficient chances exist to train students efficiently so that they can learn how to make desirable decisions.

In the field of business management, a decisionmaking method and an optimization theory are addressed as one topic among important issues. A solution is obtained rationally using a mathematical method. It is generally difficult to prove its effectiveness. Therefore, it is not easy for students to use the method in a practical way. Many business management lessons or operations-research lessons examine decision-making methods. Regarding decision-making methods, students must learn how to make rational decisions. Linear programming methods can indicate a point at which to gain a maximum profit under some conditions or how to reduce costs to the greatest degree.
This method is typically applied to calculate transportation costs. When plural decision makers exist, game theory is effective for them to choose an appropriate option to obtain the most optimum outcome: gaining a maximum profit. According to game theory, two cases exist: a cooperative game played when decision-makers can mutually collude; and a non-cooperative game with decision-makers who cannot mutually collude.

Both decision-making methods and game theory demand higher mathematics. Therefore, it can be said that these methods are unfamiliar to students who are not good at mathematics. For this reason, when a teacher explains a rational decision-making method to students, it is extremely important to create new teaching materials showing how to make students understand an outline of decision-making methods without using a technique requiring high mathematical calculation skills. The next four steps show the decision-making method learning process of Analytic Hierarchy Process (AHP), a decisionmaking method.

1) Basic knowledge about decision-making methods and optimization theory

2) Basic learning related to AHP

3) Application of AHP

4) Collaborative lessons using decision-making methods with an education institution in a foreign country

This educational practice reports that educational effects were closely examined to ascertain whether learning steps were practiced successfully or not from the third learning step to the fourth learning step.

\subsection{Prior learning related to AHP}

To date, surveys have examined several practices in learning an optimum decision-making choice, using robotic cars or robotic trains, and education effects [6]. Students watched three running patterns and thought about an optimum running pattern independently after they calculated the weight of running patterns using criteria for assessment that had been presented to them in advance.

In this practice, the following four knowledge items are needed: understanding mathematical rationality related to AHP decision-making theory, an eigenvalue, a calculation of weight based on a vector calculation, and understanding a degree of adjustment indicating the degree of contradiction between making decisions. After students acquire four important points of understanding, they are prepared to examine a running robotic car or a running robotic train.

Students learned collaboratively with other students at an education institute in a foreign country, using a robotic car as a teaching material. In this educational practice, all students first estimated 
an optimum running pattern and expressed their ideas before running a robotic car. Actually, students needed to ascertain the optimum running pattern. However, students could not conduct a deep discussion with students in a foreign country because it was hard for students in Japan to discuss the matter in English. Two reasons were cited: Japanese students were unable to communicate well with each other because the lesson was conducted in English, and understanding of a rational decision-making method was not sufficiently good for them.

Through these practice iterations, the authors learned that two viewpoints are necessary to activate a collaborative activity with students at an education institute in a foreign country.

1) Provide a lesson to learn an AHP outline concisely 2) Alleviate as much anxiety as possible from students who are not good at communicating in English by giving a preparation lesson in English

The authors gave students a lesson in English focused on learning decision-making methods, and measured its effects.

\section{Learning decision-making methods in English}

Learning using robotic cars is applicable to learning a specialized subject combined with mechanics, control engineering, electricity, and so on. For instance, the authors applied robotic cars to learning decision-making methods, and expanded a lesson of learning decision-making methods to collaborative learning with an education institute in a foreign country for developing global human resources.

Previous collaborative learning using robotic cars demonstrated that students were unable to concentrate on their learning, and that collaborative learning provided additional burdens to them because they were lacking good communication skills in English. Moreover, they were not well trained in advance.

For these reasons, the authors created new learning lessons: before collaborative learning with an education institute in a foreign country was practiced, lessons related to decision-making methods were taught by a Japanese teacher (Teacher A) and a foreign teacher (Teacher B), to change student awareness of English and to raise student awareness of learning a specialized subject in English. The change of student awareness was examined closely after the lessons were completed.

Lessons were planned as follows. Eight students participated in the lessons. During the first lesson, Teacher A explained the lesson purpose. The purpose of the lessons was to ascertain the necessity of rational decision-making methods, to alleviate fear of English from the students by learning several specialized terms in English beforehand, and to have awareness of the effectiveness of rational decisionmaking methods, using one decision-making method in a simple manner.

Next, Teacher B is an engineering field researcher. He explained his own research field in English, but he was sometimes asked questions by the students both in English and Japanese. Teacher A sometimes provided additional explanations in Japanese for Teacher B, and devoted attention to increasing students' understanding by communicating with students to support Teacher B (See Figure1).

Students were allowed to ask questions in Japanese for fear that they might stop communicating with Teacher B. In other words, the lessons were conducted in cooperation with Teacher A, Teacher B, and the students, mutually communicating in both English and Japanese.

During the next lesson, Teacher B explained what they thought about choosing a job, and what possible jobs were left for him to choose at that time. The students were allowed to ask questions both in Japanese and English. After this activity, Teacher A introduced a simple method of decision-making to the students. Teacher A made a chart of Teacher B's decision-making process, and proved that Teacher B's choice of occupation was the most important for him using figures. The lesson was conducted in Japanese and in English.

In the lesson, Teacher A explained Teacher B's decision-making process simply, using the AHP hierarchy. The goal, criteria, and alternatives are generally determined in advance, according to the AHP method. The weight of importance is decided according to a pair comparison of criteria.

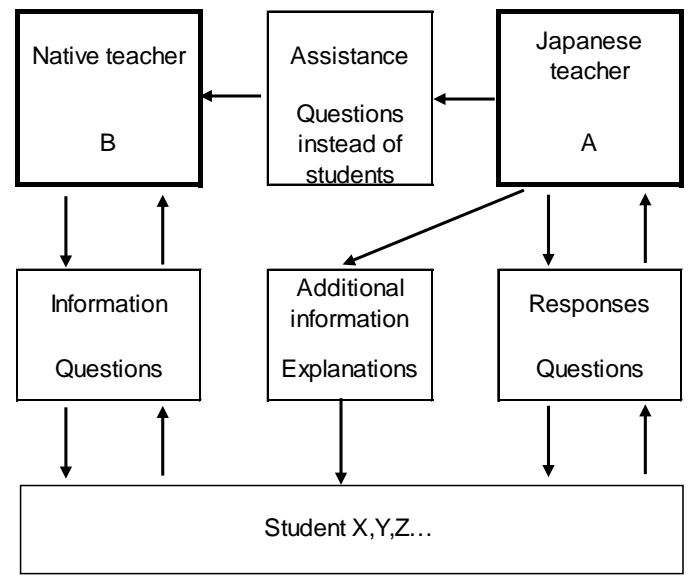

Figure 1. Relations between teaching and learning

Next, the weight of importance is decided using a pair comparison between alternatives that are available under each criterion. Finally, a consistency index is examined to avoid glaring contradictions.

Reconsideration of comparisons is said to be desirable if the number of consistency index is big. This lesson aims at learning technical terms in 
English and at raising students' motivation to learn specialized subjects in English through communication with teachers in English. Therefore, students were made to decide the weight of importance by getting the total number to be 1 without using a pair comparison.

Students were assigned to think about a career design of their own. They calculated figures used in the same decision-making method and examined which was the most important for them. For this lesson, students were asked to write a report in English. Teacher B checked each of their reports written in English and corrected their reports in faceto-face communication with the students.

\section{Analysis and Consideration}

Before the first lesson started, and again after all the lessons had been completed, a questionnaire was administered to eight students to assess their awareness (See Table 1) using five scales. The five scales were categorized as follows: 5 . strongly agree to have; 4. Agree to have; 3. Neither agree nor disagree to have; 2 . Disagree to have, and 1 . Strongly disagree to have.

It was examined using a Wilcoxon signed rank test. Results show that the students' awareness was raised for four items at $5 \%$ significance level $(\mathrm{z}=-2.0$, $\mathrm{p}<0.05$ ): 5 . Ability to describe the student's ideas; 10. Ability to complete a task and carry it out; 19 . Will to write in English; 20. Interest to learn a specialized subject in English. Results show that the students were able to concentrate on learning a decision-making method by being allowed to use Japanese language during class, even though Teacher A and Teacher B collaborated as a team speaking in English during the lessons, encouraging the students to use English as frequently as possible.

During the lessons, Teacher A and Teacher B were able to lead the students to become interested in learning a specialized subject in English. They raised student awareness in writing a report in English, even though the students were allowed to speak in both Japanese and English. This educational practice suggests that teachers can soften students' strained feelings in responding to a foreign teacher in English, and that they can support students in Japanese to succeed in learning a specialized subject in English.

The eight students were asked to list the learning activities that were useful to improve their awareness. Questionnaire items and the method of analysis were
Table 1. Questionnaire about Students' Awareness

\begin{tabular}{|c|c|c|c|c|}
\hline Item & & & \multicolumn{2}{|c|}{$\begin{array}{c}\text { After } \\
\text { Activities }\end{array}$} \\
\hline 1. Will to have communication & 4.1 & 0.4 & 4.4 & 0.5 \\
\hline 2. Ability to summarize student ideas & 4.0 & 0.5 & 4.4 & 0.5 \\
\hline 3. Ability to analyze oneself & 3.4 & 0.9 & 4.0 & $0.5+$ \\
\hline 4. Ability to consider and judge independently & 3.6 & 0.9 & 4.1 & 0.8 \\
\hline 5. Ability to describe student ideas & 3.1 & 1.1 & 3.6 & 1.1 * \\
\hline 6. Ability to explain the student ideas precisely to others & 3.3 & 0.7 & 3.6 & 1.2 \\
\hline 7. Ability to listen to others and ask them questions & 3.1 & 1.0 & 3.6 & 1.2 \\
\hline 8. Ability to evaluate appropriately what the student considers & 3.5 & 0.8 & 3.6 & 0.7 \\
\hline 9. Ability to respect others' ideas & 4.4 & 0.5 & 4.4 & 0.7 \\
\hline 10. Ability to complete a task and carn & 3.6 & 0.9 & 4.1 & 0.8 * \\
\hline 11. Ability to solve the student's own problem & 3.8 & 0.7 & 4.0 & 0.5 \\
\hline 12. Ability to make a plan by oneself & 3.5 & 0.9 & 3.8 & 0.7 \\
\hline 13. To create a new thing independently & 3.0 & 1.1 & 3.4 & $1.3+$ \\
\hline 14. Ability to think in English & 3.5 & 0.8 & 3.8 & 0.9 \\
\hline 15. Ability to think things over with a wide field of vision & 3.8 & 0.9 & 3.9 & 1.1 \\
\hline 16. Interest and curiosity in English & 4.5 & 0.5 & 4.3 & 0.7 \\
\hline 17. Ability to think about the student's future & 4.5 & 0.5 & 4.9 & 0.4 \\
\hline 18. Will to read books in English & 4.1 & 0.6 & 4.4 & 0.7 \\
\hline 19. Will to write in English & 3.6 & 0.7 & 4.1 & 0.6 * \\
\hline $\begin{array}{l}\text { 20. Interest to learn a specialized subject in English } \\
{ }^{*} p<0.05+p<0.1\end{array}$ & 3.4 & 1.1 & 3.9 & 0.6 * \\
\hline
\end{tabular}

referred from Miyaji [7]. The learners' awareness of 20 types shown in Table 1 and the activities of 17 types shown in Table 2 were presented to them. The number of listed activities was cross-tabulated with awareness and activities. Then a cross-tabulation table was made. A cluster analysis was conducted using Ward's method with awareness as cases and activities as variables. Results show that awareness can be categorized into three clusters: I, II, and III.

Cluster I comprises items 1, 5, 6, 14, 18, 19, and 20, which are related to an interest and concern for English. Cluster I was designated as "Awareness of improving English skills.” Cluster II, comprising items 7, 9, and 15, was designated as "Awareness of improving perception." Cluster III, comprising Items $2,3,4,8,10,11,12,13$, and 17 , which are related to planning and analysis, was designated as "Awareness of improving planning and analysis abilities."

Next, another cluster analysis was conducted with activities as cases and awareness as variables. The activities were also categorized into three clusters: 1 , 2, and 3. Cluster 1 includes activities 10, 12, 13, 14, 15 , and 16, which are related to activities of making documents and doing revisions of English. Cluster 1 was designated as "Activities of writing and revising in English." Cluster 2 comprises activities 1, 2, 3, 4, and 5 , which are related to the activities of listening

Table 2. Learner activities

1. To listen to teachers about a decision-making method

2. To ascertain why the student should join lessons conducted in English

3. To listen to teachers' studies

4. To listen to why teachers chose the current work

5. To listen to teachers about how to decide

6. To consider teachers' decision-making

7. To make a chart of a teacher's decision-making

8. To calculate results of a teacher's decision making

9. To consider the student's future plan

10. To express the student's future plan to others

11. To calculate results of the student's future job

12. To listen to the teacher's explanation in English

13. To take a lecture about how to write a paper in English

14. To write an abstract of the student's research paper in English

15. To listen to teachers about what to revise in an abstract

16. To ask teachers in English

17. To evaluate a student's abilities and awareness of lessons 
to teachers and considering things learned. Cluster 2 was designated as "Activities of listening to others and considering." Cluster 3 contains activities 7, 8, 9, 11 , and 17 , which are regarding the activities of using a decision-making method. Cluster 3 was designated as "Activities of using a decision-making method."

Frequencies of each cluster were added to the cross tabulation table (20 rows and 17 columns). The observed frequency is shown in the $3 \times 3$ cross tabulation (See Table 3). Results show a significant relation between awareness and activities $\left(\chi^{2}(4)\right.$ $=168.3, \mathrm{p}<0.01)$. The result of residual analysis is presented in Table 3.

These cells among the positive adjusted residuals for which significance was indicated were assigned an asterisk $\left(^{*}\right)$, as shown in the significance test column of Table 3. Results showed that Activities of 1 were helpful to improve Awareness I, Activities of 2 were helpful to improve Awareness II, and Activities of 3 were helpful to improve Awareness III.

The activities of writing and revising in English enhanced students' awareness of improving English skills. Results further showed that activities of listening to others and considering enhanced students' awareness of improving students' understanding, and that activities of using decisionmaking methods enhanced students' awareness of improving planning and analysis abilities.

\section{Communication activities to raise student motivation}

Problems arise when Japanese people are involved in business with foreign people because they are not accustomed to communicating in English.

They feel difficulty in continuing communication with foreigners after short greetings and a simple self-introduction are exchanged in English. They feel unconfident in communicating with foreigners in English when they have no common topic for better communication because they lack experience in leading a conversation with foreigners who are not accustomed to Japanese culture.

They also feel that they are not good at speaking in English. However, in a globalized society, English is used as a communication tool. It is an urgent issue for Japanese people to acquire communication skills in English to cope with cross-cultural society [8].

Therefore, the authors designed a lesson to resolve such communication problems and to carry out cross-cultural activities at school so that Japanese college students can experience communication with foreign students in English, thereby increasing their motivation in learning English[9]. Herein, the authors report details of an educational practice because Japanese students' motivation was raised after they prepared questions for a communication lesson and experienced interactive activities with foreign students in a learner-centered manner.

\subsection{Communication activities with student interns from abroad in 2013}

Language learning becomes more active when students are given a chance to learn a target foreign language in a learner-centered way while mutually interacting. In such cases, students have more opportunities to be involved in learning a target language and using it more often than when they learn in a teacher-directed manner [10]. It is also readily apparent that student motivation is higher when their attention is devoted more to learning contents than when their attention is devoted solely to a target language itself [11].

Depending on the two ideas presented above, the authors designed a lesson to practice learner-centered

Table 3. Results of Observed Frequency and Residual Analysis

\begin{tabular}{|c|c|c|c|c|c|c|}
\hline \multirow[b]{2}{*}{ Clusters related to awareness/activities } & \multicolumn{3}{|c|}{ Observed Frequency } & \multicolumn{3}{|c|}{ Expected Frequency } \\
\hline & 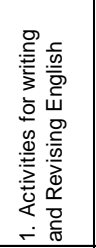 & 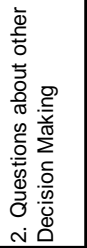 & 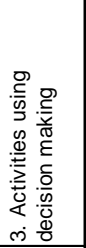 & 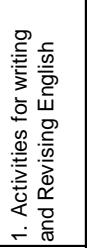 & 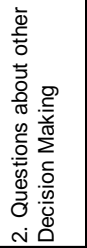 & 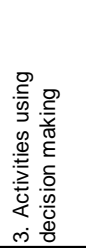 \\
\hline I. Awareness of Thinking and Writing in English & 293 & 129 & 102 & 233.4 & 133.1 & 157.5 \\
\hline II. Awareness of Understanding of Others & 72 & 109 & 46 & 101.1 & 57.7 & 68.2 \\
\hline III. Awareness of independent consideration & 161 & 62 & 207 & 191.5 & 109.2 & 129.3 \\
\hline \multirow[t]{2}{*}{ Total } & 526 & 300 & 355 & 526 & 300 & 355 \\
\hline & \multicolumn{3}{|c|}{ Results of Residual Analysis } & \multicolumn{3}{|c|}{ Significance Probability } \\
\hline I. Awareness of Thinking and Writing in English & 7.0 & -0.6 & -7.1 & ** & & \\
\hline II. Awareness of Understanding of Others & -4.3 & 8.7 & -3.6 & & ** & \\
\hline III. Awareness of independent consideration & -3.7 & -6.6 & 10.3 & & & ** \\
\hline
\end{tabular}


activities based on problem-based learning in 2013. The lesson is for Japanese students to share communication activities with students from abroad.

Japanese students prepare for them independently before the lesson. They decide what topic they are going to talk about, and formulate questions independently. Activities prepared by students yield an autonomous learning environment and activate students because students already know what to do during the lesson. During lessons, they ask foreign students various questions in a group, using a student-made question sheet[12]. A teacher's role during a lesson is to be a good time keeper, so that students can have responsibilities for their activities. In this way, Japanese students reduce their anxieties in communicating with foreign students[13].

Since 2012, College A has accepted students from Asia as non-registered students. Non-registered students stay at College A for 1-3 months as internship students. They join lessons to study or conduct research with Japanese college students. For example, in 2013, a group of four students from Thailand stayed at College A during April-May, a group of four students from Singapore stayed during April-July. Another group of four students from Singapore stayed during September-December. These students were invited to join English communication activities three times in 2013.

They shared interactive activities with Japanese students of various grade levels. The purpose of communication lessons is for Japanese students to enjoy cross-cultural activities with foreign students, and to increase their motivation for communicating in English. Characteristics of the interactive activities are presented here.

1) Japanese students produce questions independently, which motivates them to participate in communication activities. The question sheet works as a scenario with many blank spaces for foreign students to fill in. The question sheet helps the Japanese students develop their communication cooperatively with foreign students [14].

2) The Japanese students can repeat their questions in one lesson and participate in interactive activities without feeling bored because they meet a new foreign student every 10 minutes [15].

\subsection{Teaching procedure using a student- made question sheet}

A student-made question sheet helps students to share information about speakers' turns and their topics. Students can talk about a different topic in a real activity. The following teaching procedure was used:

1) Japanese students formulate questions both in English and Japanese to ask short-term students.

2) All questions produced by the Japanese students are checked by a teacher and are kept together on a sheet of paper. The question sheets are returned to the Japanese students and are shared among them.

3) The Japanese students are separated into several groups according to the number of foreign students. One group consists of one short-term student and 56 Japanese students.

4) Each Japanese student asks a foreign student a question by turns. Japanese students write replies on the question sheet. The question sheet works as a scenario.

5) In 10 minutes, a short-term student changes a group and moves to another group. Japanese students repeat the same questions to a new short-term student from abroad, but they receive different replies.

6) The Japanese students write their comments on the question sheet and submit the sheet to a teacher at the end of all activities.

\subsection{Analysis and consideration}

The practical communication activities were conducted twice with 37 students in the fifth year in 2013. In April 2013, before activities started, 10 out of 37 students expressed the goal they would like to reach in ambiguous terms such as 'enjoying a practical conversation in English' and 'having a daily conversation.' However, in July 2013, after the activities finished, 13 out of 37 students expressed their thoughts and feelings in rich vocabularies.

Summing up, 38\% of the 37 students regarded the practical communication activities with foreign students as a useful activity.

Next, the 37 students assessed themselves in the practical communication activities related to three items presented in Table 4 using five scales. The five scales were categorized as follows: 5, I strongly agree; 4, I agree; 3, Neither to say; 2, I do not agree; and 1, I definitely do not agree. The 37 students assessed themselves in the practical communication activities three times, in April, May, and July in 2013, every time they finished activities each month.

Of the 37 students, 34 responded three times to the questionnaire. Their answers were analyzed. The average score of 34 students' total scores each month is shown in Table 4. All items increased between April and July at a 1\% significance level according to the t-test.

Table 4 data show that the three average scores of students' self-assessments are lower than 3.0. However, the three average scores in April increased in July. Table 4 portrays a tendency of a group of 34 students that they realized that their communication skills in English rose through learning English in a practicable way.

The practical communication activities produced three hints about how to improve communication skills. 
Table 4. Average score of students’ self-assessment related to three items

\begin{tabular}{|c|c|c|c|c|c|c|c|c|}
\hline \multirow{2}{*}{ Items } & \multicolumn{2}{|c|}{ April } & \multicolumn{2}{|c|}{ May } & \multicolumn{2}{|c|}{ July } & \multirow{2}{*}{$\begin{array}{c}\mathrm{t}^{-} \\
\text {value }\end{array}$} & \\
\hline & Mean & S.D. & Mean & S.D. & Mean & S.D. & & \\
\hline $\begin{array}{l}\text { 1. I can convey my feeling } \\
\text { or thought in simple } \\
\text { English. }\end{array}$ & 2.7 & 0.9 & 2.9 & 0.8 & 3.1 & 1.1 & 3.0 & $* *$ \\
\hline $\begin{array}{l}\text { 2. I can ask a simple } \\
\text { question to foreigners } \\
\text { listening to them. } \\
\text { 3. I think I have }\end{array}$ & 2.6 & 1.0 & 2.8 & 0.9 & 3.2 & 1.1 & 3.5 & $* *$ \\
\hline $\begin{array}{l}\text { communication skills in } \\
\text { English. } \\
\qquad * * p<0.01\end{array}$ & 2.5 & 0.8 & 2.7 & 0.8 & 3.1 & 1.0 & 3.1 & $* *$ \\
\hline
\end{tabular}

1) Japanese students formulated questions, shared them in a class and understood future developments. Foreign students might also guess up-coming developments by reading the question sheet. Sharing up-coming plans or development can make their communication more active.

2) Japanese students asked foreign students the same questions repeatedly. Asking questions can make the Japanese students continue their communication smoothly.

3) Japanese students received different reactions and favorable replies from the foreign students of the same generation. The interactive activity with the same generation enlivens their communication.

\section{Students' self-assessment results in 2014}

Educational practice in 2013 revealed student feelings that their English communication skills developed and that their motivation was stimulated by the lessons. Therefore, in 2014, the authors conducted communication activities for another group in the second year twice to confirm whether activities in 2014 work as well as they did in 2013.

Details of educational practices in 2014 are described next. During April-July in 2014, eight students from abroad stayed at College A: four students from Thailand stayed during April-June; four students from Singapore stayed during AprilJuly. The eight students were invited to a group of 37 students in the second year in May. The teaching procedure in 2014 was taken over from that in 2013. In a prior lesson, Japanese students made questions by themselves and practiced a short self-introduction in English: "My name is .... Please call me.... Nice to meet you. My question is ...." The role of teachers was to keep time. Students' autonomy was respected during the activities. After the interactive activities, 37 students wrote short comments about their activities.

Another group of four students from Singapore stayed during September-December in 2014. The 37 students had communication activities in October using a different question sheet made by themselves. The short comments they wrote after the lesson in October were compared to those in May.
In May, 13 of 37 students used negative expressions to assess their activities. For example, students reported that English is difficult and that English conversation is difficult. Only 7 students thought that communication activities with foreigners were fun.

However, in October 13 students used positive expressions to state that it was good to have interactive activities. Only five students used negative expressions for their self-assessment. The group tendency is presented in Table 5 .

Four students in October expressed positively that their English had improved, saying that they were better able to comprehend what foreign students spoke about than before and stating that they understood their English better; they comprehend what they said better than before; they were able to speak more than before; and a larger vocabulary was actually used. These comments underscore that cross-cultural activities influence Japanese students' awareness of learning English and give them a chance to develop the talents necessary to have a global perspective through interaction with students who have a different culture. A student-formulated question sheet and interactive activities repeated every 10 minutes encourage Japanese students to develop English communication skills.

\section{Conclusions}

The two educational methods and practical results suggest that the following two points are effective to develop problem-based learning in English using robotic cars and trains in future instruction.

1) Students should be encouraged to concentrate on their tasks through solution of a problem, instead of particularly addressing communications using only English. It is difficult for students to concentrate on given tasks and to carry them out if they take lessons using only English.

Results show that they can improve their knowledge and skills of decision making and that they can enhance their planning ability and analytical ability through learning a decision making method by lessons using English and Japanese. Students also think that they can maintain their willingness to write and interest in learning a specialized subjects in English.

Table 5. Analysis of 37 students' comments in the

\begin{tabular}{|l|l|l|}
\multicolumn{3}{c}{ second year } \\
\hline Student comments & May, 2014 & October, 2014 \\
\hline Negative expressions & $35 \%$ & $13.50 \%$ \\
\hline & $\begin{array}{l}\text {-because of poor } \\
\text { listening \& speaking skill } \\
\text {-bad pronunciation } \\
\text {-English is difficult }\end{array}$ & $\begin{array}{l}\text {-because of poor listening } \\
\text { ability } \\
\text {-English is difficult }\end{array}$ \\
\hline Positive expressions & $18.90 \%$ & $35 \%$ \\
\hline Examples & -fun & $\begin{array}{l}\text {-fun } \\
\text {-it's good to have } \\
\text { interactive activities }\end{array}$ \\
\hline
\end{tabular}


2) Students are encouraged to discuss collaborative activities in advance and to deepen their knowledge so that they can seek better communications.

The second educational practice suggests that students can communicate effectively in English if they have a good preparation for discussion in English.

From the two educational practices, it is concluded that lessons in both English and Japanese are extremely useful so that students can learn specialized subjects, use them in real situations, and make practical use of them from a global perspective. It is also important for students to obtain training through lessons to communicate with others in English in advance.

\section{Acknowledgement}

This work was supported by a Grant-in-Aid for Scientific Research (C) (No. 24501170).

\section{References}

[1] N. Fujishiro and I. Miyaji, "Effectiveness of Blended Instruction in Class on the Skills of Oral Reading and Speaking in English”, Educational Technology Research, Vol. 32, No. 1, 2009, pp. 79-90.

[2] K. Nohara, S. Kawamoto, and O. Kusakabe, “An Attempt of International Liberal Arts Education for Nurturing "Global Engineers" at Tokyo Institute of Technology", Journal of Japan Society for Engineering Education, Vol. 56, No. 4, 2008, pp. 114-122.

[3] O. Furuya, O. Bright, and T. Saika, "English Curriculum in Global Engineer Education Program", Journal of Japan Society for Engineering Education, Vol. 56, No. 4, 2008, pp. 21-26.

[4] Y. Naruse, I. Miyaji, S. Toga, Y. Hayase, and Y. Hayakawa, "Educational Effect on Analyzing Others' Experimental Products", Proceedings of Society for Information Technology \& Teacher Education International Conference, U.S.A., 2013, pp. 3996-4000.

[5] P. R. Drake, "Using the Analytic Hierarchy Process in Engineering Education”, International Journal of Engineering Education, Vol. 14, No. 3, 1998, pp. 191-196.

[6] Y. Naruse, "A Study of the Class of Learning Optimal Decision Making Using AHP”, Journal of Japan Society of Educational Information, Vol. 25, No. 1, 2009, pp. 25-35.

[7] I. Miyaji, "Comparison between Effects in Two Blended Classes Which E-learning is Used inside and outside Classroom”, US-China Education Review, U.S.A., Vol. 8, No. 4, 2011, pp. 468-481.

[8] Harmer, J., The Practice of English Language Teaching, Pearson Education Limited, England, 2001.

[9] Aubrey, S., "Development of the L2 Motivational Self System: English at a University in Japan”, Journal of
Japan Association for Language Teaching, Vol. 36, No. 2, 2014, pp. 153-174.

[10] Richards, J.C., W.A. Renandya, Methodology in Language Teaching, Cambridge University Press, U.K., 2002.

[11] Coyle, D., P. Hood, and D. Marsh, Content and Language Integrated Learning, Cambridge University Press, U.K., 2010.

[12] H. Kobayashi, and K. Hirose, "Japanese Learners' Repetition in Conversation in Relation to English Proficiency Level", Journal of Japan Association for Language Teaching, Vol. 17, No. 1, 1995, pp.53-73.

[13] Dörnyei, Z., Teaching and Researching Motivation, Pearson Education Limited, U.K., 2001.

[14] Nunan, D., Collaborative Language Learning and Teaching, Cambridge University Press, U.K., 1992.

[15] Coady, J., and T. Huckin, Second Language Vocabulary Acquisition, Cambridge University Press, U.K., 1997. 